SILVA, J. P. B. (2020)

0 sentido de filosofar em sala de aula

DOI: $10.31416 /$ rsdv. v8i2. 57

\title{
O sentido do filosofar em sala de aula - experiência das aulas de Filosofia ministradas em uma turma de ensino médio da EREM Fernando Bezerra
}

\author{
The meaning of philosophizing in the classroom - Experience of Philosophy classes \\ taught in high school class at EREM Fernando Bezerra
}

Silva, João Paulo Bastos da. Mestre em Filosofia pela Universidade Federal de Pernambuco - UFPE/Licenciado em Filosofia pela Faculdade de Filosofia, Ciências e Letras de Cajazeiras - FAFIC. E-mail: professorjpbastos@gmail.com

\section{RESUMO}

Abordamos, no presente artigo, o projeto de intervenção das aulas de Filosofia realizadas em uma turma do $1^{\circ}$ ano do ensino médio na EREM Fernando Bezerra. A metodologia utilizada, nesta intervenção, tem como ponto de partida a caracterização e fundamentação dos quatro passos didáticos - Sensibilização, Problematização, Investigação e Conceituação, que foram o marco inicial para abordarmos o sentido do filosofar em sala de aula em direção à construção e produção das experiências dos alunos com o conhecimento filosófico. Sobre o sentido do filosofar, estabelecemos uma relação entre Filosofia e o filosofar, à luz da reflexão e da abordagem dos filósofos contemporâneos Comte-Sponville, Alejandro Cerletti, Alain Badiou e Jacques Derrida. Através desta abordagem, os alunos adentraram na experiência do filosofar, sendo convidados a refletirem e vivenciarem a experiência do filosofar como produção de sentido, através do vasto universo de conhecimento de cada aluno e das suas visões de mundo. 0 objetivo consistiu em conduzir o aluno para exercitar o seu senso crítico e desenvolver sua própria autonomia na aventura do pensamento filosófico. O professor de Filosofia tem uma missão importante, que é conduzir o aluno em uma Filosofia sem fronteiras em direção ao filosofar, estimulando-o a exercitar a reflexão filosófica e a abertura dos diferentes pontos de vista.

Palavras-chave: Filosofia; Filósofo; Filosofar; Professor; Sala de aula.

\begin{abstract}
In this article we approach the intervention project of Philosophy classes held in a class of the 1st year of high school at EREM Fernando Bezerra. The methodology used in this intervention, has as a starting point the characterization and justification of the four didactic steps; Awareness, Questioning, Research and Conceptualization, which were the initial milestone in which we approach the meaning of philosophizing in the classroom towards the construction and production of students experiences with philosophical knowledge. Regarding the meaning of philosophizing, we established a relationship between philosophy and philosophizing, in the light of the reflection and approach of contemporary philosophers: Comte-Sponville, Alejandro Cerletti, Alain Badiou and Jacques Derrida. Through this approach, students enter the experience of philosophizing, where they were invited to reflect and experience the experience of philosophizing as a prodution of meaning, through the vast universe of knowledge of each student and their worldviews. The objective was to guide the student to exercise his critical sense and develop his own autonomy in the adventure of philosophical thought. The philosophy teacher has an important mission, to lead the student in a philosophy without borders towards philosophizing, stimulating the same, to exercise philosophical reflection and the opening of different points of view.
\end{abstract}

Keywords: Philosopher; Philosophy; Philosophize; Teacher; Classroom. 
SILVA, J. P. B. (2020)

O sentido de filosofar em sala de aula

\section{Introdução}

A sala de aula é um espaço onde vivenciamos o imprevisto dos encontros e acontecimentos, seja por parte dos alunos ou pelo próprio professor. Sempre estamos a par de novas ideias, novos fatos e situações que nos antecedem no cotidiano deste espaço e tempo que caracterizamos como ambiente escolar. Neste sentido, damos asas às nossas imaginações, refletimos sobre a vida, pensamos sobre a nossa condição no mundo, e nos interrogamos sobre a nossa própria existência.

0 presente artigo é fruto de um trabalho realizado em sala de aula no primeiro semestre do ano de 2019, na Escola de Referência em Ensino Médio Fernando Bezerra, que fica localizada na cidade de Ouricuri - PE. A referida escola é estadual e funciona em tempo integral, pertencente à Secretaria de Educação de Pernambuco, sob a jurisdição da GRE Sertão do Araripe. Escolhemos a turma de $1^{\circ}$ ano " $A$ " para realizamos a nossa intervenção levando em consideração que estes alunos nunca tiveram contato com o ensino de Filosofia no ensino fundamental II, ou seja, estão tendo a oportunidade de aprofundar conhecimentos acerca da disciplina filosófica pela primeira vez no ensino médio.

O objetivo desta intervenção consistiu em repensar as aulas de Filosofia para os alunos das turmas iniciantes do ensino médio, através de temáticas que estejam relacionadas com o filosofar, estimulando o aluno para investigação do pensamento filosófico. É preciso que nas aulas de Filosofia o aluno esteja envolvido nas discussões das temáticas abordadas tanto no contexto que envolve a sala de aula, como também no que esteja relacionado com o seu cotidiano. É preciso sair dos conteúdos privados que impedem o aluno de desenvolver e exercitar o seu pensamento; é preciso que nas aulas filosóficas as experiências e os pensamentos dos sujeitos sejam contemplados como uma produção de sentido para o acontecimento do filosofar em sala de aula.

No transcorrer deste artigo, apresentaremos os passos didáticos que foram fundamentais para a realização destas aulas. A participação dos alunos foi de fundamental importância, pois percebemos que cada um deles se sentiu valorizado e, ao interagirem nas aulas, expressaram suas diversas manifestações acerca da compreensão do pensamento filosófico, demostrando interesse pela Filosofia, para assim poderem exercitar o seu senso crítico e desenvolver sua autonomia através de si mesmos, dos outros e do mundo que os cerca.

Abordamos nestas aulas a temática voltada para as concepções do filosofar em torno das ideias propostas por Comte-Sponville, Alejandro Cerletti, Alain Badiou e Jacques Derrida. Escolhemos estes filósofos contemporâneos porque eles estão intensamente ligados com as tendências que tratam do ensino de Filosofia no século XX e XXI, e suas concepções filosóficas nos direcionam a percorrermos um caminho em torno do exercício do filosofar como sendo uma construção e uma tarefa compartilhada do pensamento filosófico.

O nosso artigo está estruturado em três momentos: no primeiro, apresentamos os passos didáticos e metodológicos que resultaram no desenvolvimento da nossa pesquisa e na realização das aulas; no segundo, temos a intervenção e os relatos das experiências, bem como as atividades e os trabalhos que foram realizados pelos alunos durante as aulas; no terceiro, uma avaliação sobre as aulas, destacando as contribuições e as participações dos alunos e do professor 01, que é o responsável 
SILVA, J. P. B. (2020)

O sentido de filosofar em sala de aula

pela turma e não mediu esforços em colaborar, tendo gentilmente cedido as suas aulas para realização desta intervenção.

\section{A sequência didática das aulas}

O filósofo francês André Comte-Sponville, em sua obra intitulada "Apresentação da Filosofia", define que o processo do filosofar acontece através de um pensamento próprio e, para que isso aconteça, faz-se necessário fazê-lo de um modo válido o que, neste sentido, consiste em apoiar-se no pensamento dos outros, principalmente dos grandes filósofos do passado. 0 intuito da preparação destas aulas de Filosofia, para uma turma de primeiro ano do ensino médio, foi justamente apresentar a real importância do sentido do filosofar em sala de aula, processo este que acontece como uma produção de sentido, envolvendo as diversas formas de pensamentos tanto do professor como dos próprios alunos em sala de aula.

Utilizamos, em nossas aulas, os quatro passos metodológicos propostos por Sílvio Gallo (2012) que são: Sensibilização, Problematização, Investigação e Conceituação. Estes passos foram de suma importância e fundamentais para a concretização destas aulas, inclusive do nosso ponto de chegada, que é a familiaridade da experiência do filosofar como sendo uma produção de sentido de experiência entre os alunos e o professor.

A Filosofia é uma atividade que é exercida através do pensamento dos outros, envolvendo assim sujeitos que fazem o filosofar acontecer como uma produção de sentido. $E$ isso, ficou bastante claro e oportuno, foi uma experiência gratificante e riquíssima, pois os alunos, além de desenvolverem seus pensamentos, aventuraram-se no filosofar através de suas opiniões a respeito dos problemas que foram propostos, a partir de cada filósofo trabalhado em sala de aula.

Acreditamos que o nosso objetivo maior foi despertar nos alunos a autonomia do pensamento, pois o filosofar faz do filósofo alguém que pratica e vive a Filosofia. O viver a Filosofia implica uma produção de sentido que, neste caso, se utiliza da razão para pensar o mundo e sua própria vida, a fim de aproximar-se da sabedoria e/ou da felicidade. Assim, o professor de Filosofia tem um papel imprescindível na aventura e transmissão da aprendizagem significativa do filosofar para os seus alunos que, em alguma medida, são filósofos, produzem e vivem o pensamento.

A produção de sentido do filosofar em sala de aula é um caminho que deve ser vivenciado e percorrido entre o professor e o aluno no cotidiano escolar; afinal, o pensamento é reflexão e construção de sentidos e não é exclusivo ou privado a alguém, mas é compartilhado e tem que ser aprendido, já que ninguém nasce filósofo e a Filosofia é, antes de mais nada, um trabalho. 
SILVA, J. P. B. (2020)

O sentido de filosofar em sala de aula

\section{Intervenção em sala de aula}

A primeira aula teve início com a acolhida feita pelo professor 01, que apresentou a turma do $1^{\circ}$ ano "A" da Escola de Referência em Ensino Médio Fernando Bezerra. Após a acolhida, iniciamos a aula à luz do primeiro passo, que é a sensibilização. Então, pedimos aos alunos que dividissem a sala em quatro grupos, momento em que percebemos a familiaridade de interação de cada aluno em se aproximar de seus respectivos grupos; em seguida, denominamos, por grupo, os quatro filósofos que foram trabalhados em sala de aula: Grupo 01 - André Comte-Sponville, Grupo 02 - Alejandro Cerletti, Grupo 03 - Alain Badiou e Grupo 04 - Jacques Derrida.

Após a divisão dos grupos, começamos explanando a temática que iríamos trabalhar durante as aulas, sobre "o sentido do filosofar em sala de aula". Logo após a explanação do tema proposto, solicitamos que cada grupo escolhesse um representante para vir à frente, o qual recebeu imagens dos filósofos e seus respectivos pensamentos. Voltando aos seus grupos, foi solicitado que se discutisse com seus pares e explicassem para os demais grupos o que representaria e defenderia cada filósofo.

Após as discussões dos alunos em grupos, solicitamos que os mesmos pusessem as imagens em cima do papel madeira e as colassem de maneira ilustrativa, em forma de cartaz, para expormos junto ao painel interativo panorâmico que o professor 01 criou no início do ano letivo , com o intuito de despertar nos alunos o interesse pela História da Filosofia.

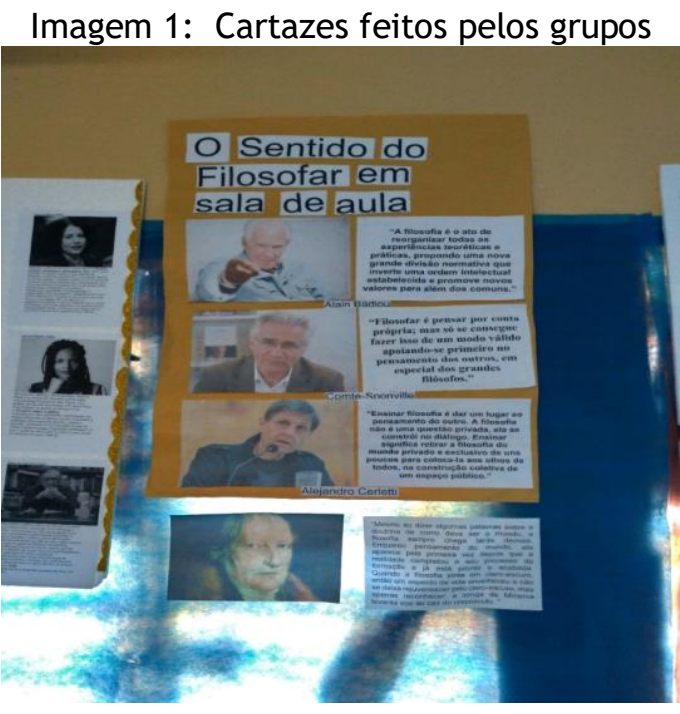

Fonte: 0 autor, 2019.

Imagem 2: Cartazes feitos pelos grupos 


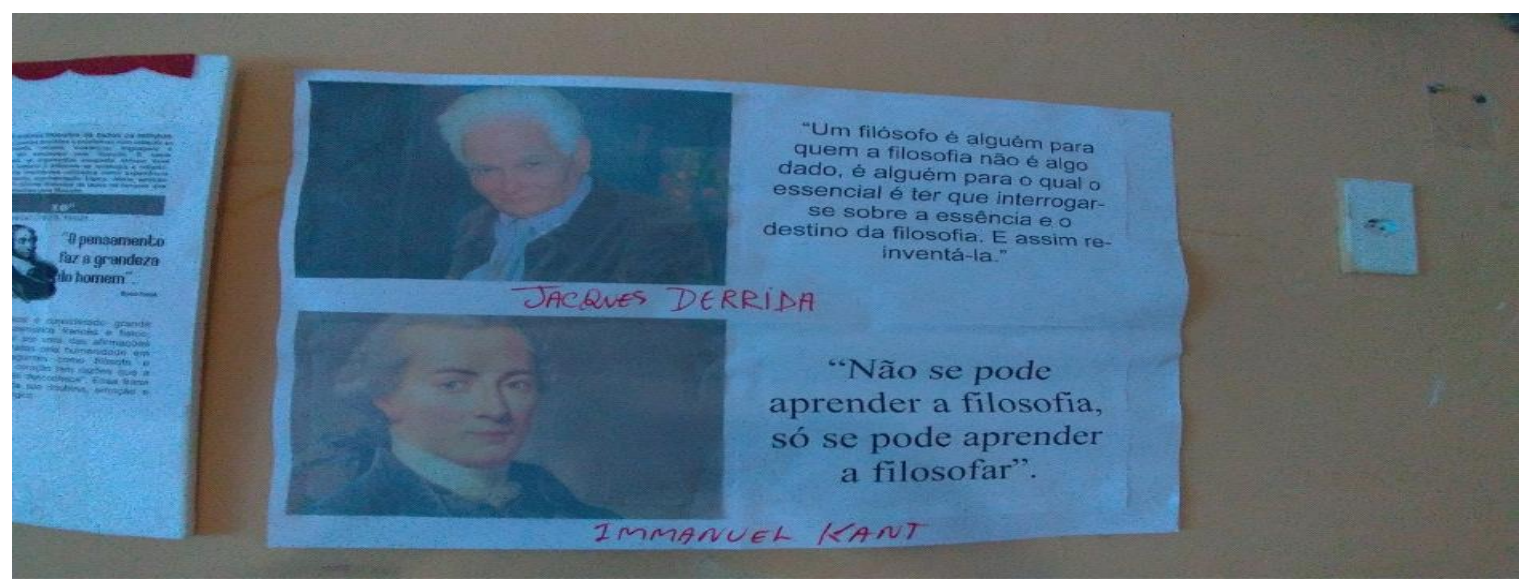

Fonte: 0 autor, 2019.

Introduzimos para os alunos o pensamento filosófico de Comte-Sponville, Alejandro Cerletti, Alain Badiou e Jacques Derrida. O mais interessante, nesta parte em que começamos a problematizar o pensamento destes filósofos, foi os alunos relatarem que não conheciam estes filósofos contemporâneos, e que estavam habituados com os Pré-socráticos, Sócrates, Platão e Aristóteles, dos quais o professor 01 tinha tratado nas aulas de Filosofia, no início do ano letivo.

Ao apresentarmos a problematização sobre a perspectiva de cada filósofo acerca do filosofar, no intuito de questionar e de provocar a reflexão nos alunos, surgiram algumas perguntas pertinentes ao assunto.

\title{
$1^{\text {a }}$ pergunta: Mas o que é um filósofo?
}

Uns grupos se reuniram e começaram a discutir sobre tal questionamento, enquanto outros ficavam bastante apreensivos, tímidos e calados. Em seguida, após as discussões, o representante de cada grupo foi convidado a vir à frente para começar a responder à pergunta: o aluno A respondeu que "um filósofo é alguém que faz e pratica a Filosofia"; a aluna B disse que "o filósofo é um pensador"; a aluna C respondeu que um filósofo "é um amante da sabedoria"; e a aluna D concordou com o aluno A, argumentando que, no entender dela, "o filósofo não só pratica a Filosofia, mas antes de tudo vive a Filosofia, que o filósofo é alguém que tem ferramentas para a construção do conhecimento" e, dessa forma, considera a Filosofia como sendo um trabalho. Tanto o aluno A como a aluna $D$ se aproximam da perspectiva filosófica de Comte-Sponville, que nos ajuda a responder esta indagação:

\begin{abstract}
“O que é um filósofo? É alguém que pratica a Filosofia, em outras palavras, que se serve da razão para tentar pensar o mundo e sua própria vida, a fim de se aproximar da sabedoria ou da felicidade. E isso, se aprende na escola? Tem de ser aprendido, já que ninguém nasce filósofo e já que a Filosofia é, antes de mais nada, um trabalho. Tanto melhor, se ela começa na escola. O importante é começar, e não parar mais. Nunca é cedo demais, nem tarde demais para filosofar, dizia Epicuro [...]. Digamos que só é tarde demais quando já não é possível pensar de modo algum. Pode acontecer. Mais um motivo para filosofar sem mais tardar. (COMTE-SPONVILLE, 2003, p. 251-252).
\end{abstract}

Continuando a discussão, partimos então para a $2^{\mathrm{a}}$ pergunta: Se o filósofo é alguém que pratica a Filosofia, então o que é a Filosofia? O aluno A respondeu que "a Filosofia é a ciência do 
SILVA, J. P. B. (2020)

O sentido de filosofar em sala de aula

conhecimento"; a aluna B disse que a Filosofia "é uma reflexão sobre a nossa própria existência"; a aluna C destacou que a Filosofia "é uma interrogação sobre a vida"; e a aluna D explicou que a Filosofia "é um caminho que nos conduz à sabedoria". Ao longo da trajetória da História da Filosofia, desde a definição do termo com Pitágoras, no século IV a.C., cada filósofo apresentou seus conceitos e suas definições sobre o termo Filosofia. Neste sentido, recorremos novamente a Comte-Sponville que nos apresenta uma definição:

A Filosofia não é uma ciência, nem mesmo um conhecimento; não é um saber a mais: é uma reflexão sobre os saberes disponíveis. É por isso que não se pode aprender a Filosofia, dizia Kant, só se pode aprender a filosofar. Como? Filosofando por conta própria: interrogando-se sobre o pensamento dos outros, sobre o mundo, sobre a sociedade, sobre o que a experiência nos ensina, sobre o que ela nos deixa ignorar... Encontrar no caminho as obras deste ou daquele filósofo profissional, é o que se deve desejar. Com isso pensaremos melhor, mais intensamente, mais profundamente (2002, p. 12).

Dando continuidade à temática da aula, elaboramos a $3^{\text {a }}$ pergunta baseada na reflexão de Alejandro Cerletti que, em sua obra 0 ensino de Filosofia como problema filosófico, lança-nos uma pergunta: "se realmente é possível ensinar Filosofia sem uma intervenção filosófica sobre conteúdos e as formas de transmissão dos "saberes filosóficos"; ou sem responder, univocamente, que é Filosofia?" (2009, p. 7).

Pedimos aos alunos que discutissem em grupo a pergunta lançada por Cerletti e, após as discussões, começamos um pequeno debate com a turma. 0 aluno A relatou que desconhecia Cerletti, mas que a pergunta é muito pertinente, pois "ensinar Filosofia requer pensamentos e que, neste caso, precisamos conhecer os conteúdos específicos da Filosofia para assim termos uma compreensão sobre os saberes filosóficos". A aluna C se identificou com as ideias de Cerletti pois, para ela, "os saberes filosóficos acontecem através do pensamento; quando estamos pensando, estamos filosofando". Para a aluna B, "é possível sim ensinar Filosofia sem uma intervenção filosófica, afinal existem pensamentos e concepções diferentes da ideia de Filosofia e do filosofar”. Já a aluna D comunga com a ideia da aluna $B$, mas acrescenta que, por haver diferentes pensamentos e concepções da Filosofia, sempre existirá um novo pensar, pois o próprio ato do filosofar requer sempre novos pensamentos; no caso em questão, precisamos retomar o que já foi pensado anteriormente por algum filósofo.

As respostas dos alunos estão em consonância com o pensamento de Cerletti que, ao enfatizar a pergunta, direciona a uma resposta:

E como sabemos, encontrar uma resposta unívoca para "que é filosofia?" não somente não é possível, mas cada uma das eventuais respostas poderia dar lugar a concepções da filosofia e do filosofar, o que influirá, por sua vez, sobre o sentido do ensinar ou transmitir filosofia. (2009, p. 11).

As discussões sobre as ideias defendidas por Cerletti foram bastante produtivas; tanto os alunos como o professor 01 gostaram da maneira como ele expõe e apresenta a Filosofia e o filosofar. 0 próprio professor 01 relatou que não conhecia Cerletti, mas se identificou bastante com as suas ideias e ficou bastante surpreso, pois, mesmo ele não sendo filósofo, sintetizou que sua prática de ensino se aproxima e está em consonância com as ideias propostas por Cerletti. 
SILVA, J. P. B. (2020)

O sentido de filosofar em sala de aula

Após discutirmos as ideias de Cerletti na aula, adentramos no pensamento de Alain Badiou, cuja Filosofia consiste em uma repetição criativa, e esta repetição é uma condição de possibilidades da criação, ou seja, do aparecimento de algo diferente. Para Badiou, em toda Filosofia sempre há algo de repetição e criação.

Apresentamos para os alunos as quatro condições do desejo do filosofar, com base em Badiou:

1) a revolta, que significa a recusa a ficar instalado e satisfeito; 2 ) a lógica, que implica o desejo de uma razão coerente; 3 ) o desejo da universidade, que denota a recusa do que é particular e fechado; 4) a aposta, isso porque a universidade não é dada de modo a priori, mas é resultado de uma ruptura com a situação, ou seja, é fruto do engajamento, e por isso, uma aposta que é o gosto pelo encontro e pelo acaso, o engajamento e o risco. 0 mundo contemporâneo é um mundo que não quer e não gosta da Filosofia, porque é avesso à revolta, à lógica, à universidade e à aposta. (1994, p. 48).

Antes de iniciarmos as discussões com os alunos sobre as quatro condições propostas por Badiou, é interessante destacar aqui que a aluna $D$ demostra uma grande proximidade com a Filosofia de Badiou, que consiste na "repetição criativa". Mesmo sem ter tido contato, anteriormente, com tal proposta filosófica, ela demostra profunda afinidade e aproximação com o filósofo, o que ficou evidente, principalmente, na discussão anterior sobre o pensamento de Alejandro Cerletti, quando destacou que "fazer Filosofia é retomar o que já foi pensado anteriormente por algum filósofo", aproximando-se assim da repetição criativa proposta por Badiou.

O aluno A começou a discussão em torno das ideias de Badiou fazendo uma alusão ao filósofo, quando diz que o mundo contemporâneo não gosta da Filosofia:

\begin{abstract}
"Se formos aplicar em nossa realidade, chegaremos à conclusão de que a Filosofia é muito importante para a formação de nossa juventude, pois a Filosofia desperta no aluno o desejo de pensar e refletir sobre o mundo e nossa realidade. Por isso que a Filosofia se torna uma ameaça e um incômodo para o sistema político, isso não somente ocorreu no período ditatorial, como também acontece nos dias de hoje, quando querem retirar a Filosofia do currículo e das escolas de ensino médio". (Relato do aluno A).
\end{abstract}

A aluna $C$ se identificou com a primeira condição apresentada por Badiou, que é a revolta; para ela, "o filósofo nunca está satisfeito, ele sempre se questiona sobre sua própria realidade". Para a aluna B, "a filosofia de Badiou é muito importante, pois suas reflexões são fundamentais e atuais, e as quatro condições que ele apresenta nos ajudam a trilhar o caminho em busca do desejo e sentido do filosofar". Para a aluna $D$, as condições do desejo do filosofar que Badiou nos propõe "são essenciais e fundamentais para nossa vida, uma vez que a Filosofia é a base do nosso conhecimento"; argumentou, ainda, que se identificou muito com a segunda condição, que é a lógica, a qual remete o filósofo, sempre, ao desejo e ao alcance de uma razão coerente.

Dando continuidade à aula, chegamos ao pensamento de Jacques Derrida, filósofo francês que em 1975, na França, foi um dos fundadores do GREPH - Grupo de Pesquisas sobre o Ensino de Filosofia, o qual tinha como objetivo reivindicar e lutar pela permanência da Filosofia no currículo do ensino secundário francês. Solicitamos, novamente, que os grupos analisassem o pensamento de Derrida, o qual defendia, abertamente, que "a Filosofia é um direito" (Du droit à la philosophie). Para Derrida, um filósofo "é alguém para quem a Filosofia não é algo dado, é alguém para o qual o essencial é ter 
SILVA, J. P. B. (2020)

O sentido de filosofar em sala de aula

que interrogar-se sobre a essência e o destino da Filosofia. E assim, reinventá-la” (1997, p. 16).

Ao iniciarmos as discussões em torno da reflexão de Derrida, a aluna $D$ frisou a importância do direito à Filosofia:

"todos nós temos o direito de estudar e aprender a Filosofia, uma vez que ao aprendermos nos tornamos cidadãos esclarecidos, pois vivemos um momento incerto em que querem retirar este direito da disciplina de Filosofia nas escolas públicas, simplesmente porque estão querendo tornar as pessoas alienadas; a Filosofia por sua vez, nos liberta da alienação, pois permite nos interrogarmos sobre a nossa vida, realidade e a nossa própria existência”. (Relato da aluna A).

Para a aluna B, "a Filosofia é muito essencial para nossa vida, pois ela é o ato de pensar o filosofar; este ato, por sua vez, nos permite refletir, para não cairmos nas armadilhas do mundo, principalmente da mídia que, ao ocupar nossas mentes, nos distancia do mundo real, tornando seres robóticos, nos privando do pensamento e alienando a nossa juventude". Já a aluna C enfatizou que "todo e qualquer direito deve ser assegurado, e que na Filosofia não seria diferente, pois se as pessoas valorizassem a Filosofia e se apossassem deste direito, teríamos pessoas menos alienadas". 0 aluno A, ao se identificar com as ideias de Derrida, salientou que a Filosofia "é algo que nos é dado através do pensamento; este direito se faz fundamental para nossa existência, pois a cada dia temos a oportunidade de reinventarmos e criarmos o nosso espaço e tempo".

Finalizamos a nossa última aula com o jogo da velha, o qual denominamos, juntamente com os alunos, de jogo da velha "filosófico", um jogo com perguntas e respostas, sobre a temática do filosofar que foram abordadas durante as aulas. 0 jogo da velha teve como objetivo principal exercitar nos alunos o aprendizado e o senso crítico em relação à vivência destas aulas, bem como o aprendizado que eles construíram acerca dos quatro filósofos que trabalhamos durantes estas aulas. Só que, desta vez, ao invés de continuarmos os mesmos grupos, propusemos uma maneira diferente: pedimos aos alunos que dividissem a sala em dois grupos, ou seja, o grupo das mulheres no lado esquerdo e o dos homens no lado direito.

O jogo foi bastante dinâmico e extrovertido, e todos participaram, inclusive os que eram tímidos e ficavam calados durante as aulas. As perguntas e respostas estavam relacionadas à temática que foi abordada durantes as aulas e aos filósofos que trabalhamos. As perguntas eram aleatórias; fizemos o sorteio para ver quem começava a responder, e as mulheres foram sorteadas, dando início ao jogo da velha. Cada grupo fazia pergunta um para o outro; se os representantes de cada grupo sorteado não soubessem a resposta, iam até o seu grupo, que os ajudaria a responder; caso o grupo não respondesse, o grupo que fez a pergunta marcava $X$ ou $O$ no jogo da velha, que estava posto no quadro branco, conforme veremos na imagem 3. 0 jogo da velha filosófico foi bastante didático e participativo; houve muita interação e participação por parte dos alunos de ambos os grupos. 0 sentido real do jogo não foi gerar uma competição para saber quem era o melhor, mas sim exercitar o pensamento dos alunos, contemplando as habilidades e os conhecimentos em relação à temática e aos filósofos que trabalhamos durante as aulas. Na primeira rodada do jogo foi empate; já na segunda, as mulheres venceram os homens por $1 \times 0$. 


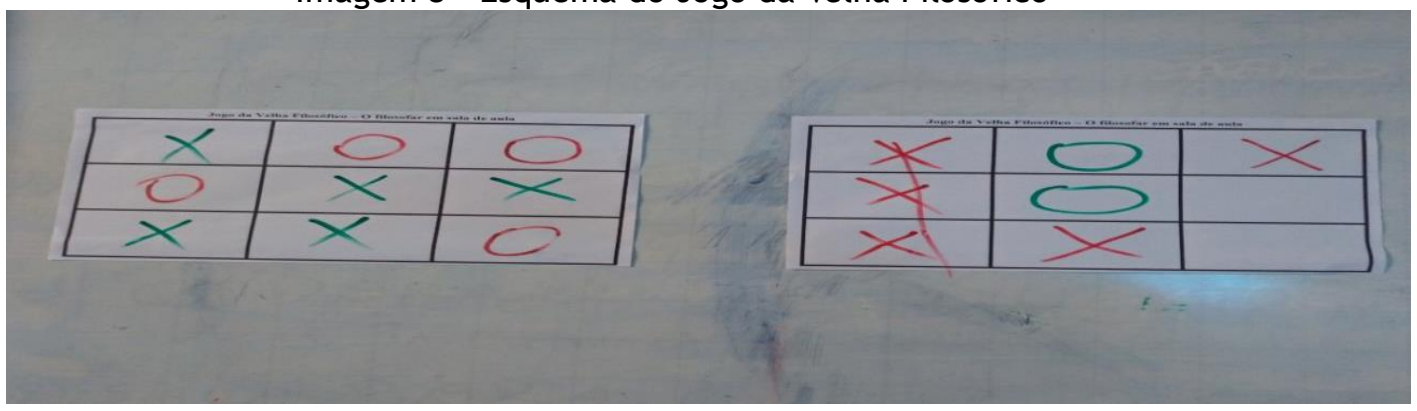

Fonte: 0 autor, 2019.

\section{Uma autoavaliação das aulas}

Trabalhamos em sala de aula o que estava previsto em nossa metodologia, que era apresentar aos alunos os quatro filósofos contemporâneos e suas reflexões sobre o ato do filosofar e da Filosofia como uma intervenção de produção de sentido e de investigação em sala de aula. Dividimos a sala em quatro grupos e começamos as discussões nas perspectivas dos filósofos Comte-Sponville, Alejandro Cerletti, Alain Badiou e Jacques Derrida. O objetivo principal destas dez aulas interventivas foi fazer o aluno refletir sobre o pensamento filosófico e desenvolver o seu senso crítico à luz do filosofar, não só através de seu próprio pensamento, mas também do pensamento dos demais.

Utilizamos como ponto de partida metodológica os quatro passos didáticos: Sensibilização, Problematização, Investigação e Conceituação. Estes passos foram de suma importância para o desenvolvimento destas aulas, como também para a interação e participação dos alunos, e para a conceituação e construção de um aprendizado significativo sobre o conceito do filosofar em sala de aula. É preciso ensinar Filosofia de uma maneira significativa, através de um convite ativo à experiência filosófica do pensamento conceitual, conforme Gallo (2012, p. 117) enfatiza: "ensinar não como ato de controle, mas como um convite a um aprendizado, a um "fazer com", à inauguração de um novo começo que nós professores não temos como saber qual será; é um ato de desprendimento e de militância".

Os conceitos dos filósofos apresentados nas aulas despertaram nos alunos curiosidades e indagações, principalmente nas questões relacionadas à investigação filosófica sobre o filosofar. Os alunos explicitaram, no relatório final da avaliação que foi solicitado para cada um, que muitas destas questões estavam relacionadas com o seu próprio cotidiano e suas próprias realidades. Nos 36 alunos (as) que compõem o $1^{\circ}$ ano "A" da EREM Fernando Bezerra, percebemos o vasto universo de conhecimento filosófico que cada um carrega em si, como bagagem para a construção dos seus próprios saberes. Alguns deles tímidos, outros calados, outros, ainda, que gostam de conversar na hora da explicação do professor, mas mesmo assim percebemos que são participativos nos trabalhos em grupos e demonstraram engajamento e afinidade com os seus pares.

Destaca-se aqui a atuação de quatro alunos - A, B, C e D, representantes dos grupos que, no transcorrer deste trabalho, tiveram uma participação ativa. $A$ aluna $D$ foi, sem dúvidas, a que mais participou durante as aulas interventivas. Ela é uma jovem de 15 anos, que nunca havia tido contato com a Filosofia, e está tendo pela primeira vez no ensino médio; gosta muito da área de humanas, 
SILVA, J. P. B. (2020)

O sentido de filosofar em sala de aula

principalmente de Filosofia, e se identifica com o pensamento de Sócrates e Nietzsche. Quando a questionei sobre o porquê dessa identidade, já que raramente é difícil encontrar jovens que gostam de Filosofia, a resposta dela foi muito pertinente e objetiva:

"Nunca tinha estudado Filosofia, meu contato com a Filosofia começou neste ano de 2019. No primeiro dia em que adentrei no recinto da sala de aula, me deparei com um panorama do percurso da História da Filosofia, que o professor 01 tinha produzido e explicado para nossa turma, que o objetivo era despertar em cada um de nós o interesse e a curiosidade pela Filosofia. Foi aí então, que neste percurso tive contato com duas frases de dois filósofos, que me chamou atenção. A primeira de Sócrates: "Só sei que nada sei", e a segunda de Nietzsche: "eu não sei o que quero ser, mas sei muito bem o que não quero me tornar". Foi a partir deste momento, de curiosidade e espanto que comecei a pesquisar no Google, sobre Filosofia, os filósofos e principalmente a biografia de Sócrates e Nietzsche”. (Relato da aluna D).

Avaliamos as aulas como positivas, principalmente no tocante à interação e participação dos alunos em relação aos conteúdos abordados. Destacamos, também, a participação efetiva do professor 01, que foi muito gratificante e proveitosa, principalmente por ele não possuir uma formação filosófica. Embora seja formado em Geografia, consegue ministrar uma boa aula de Filosofia, tem uma metodologia dinâmica, criativa e interativa; criou na sala de aula um panorama com o percurso da História da Filosofia, despertando no aluno a curiosidade e admiração pelo conhecimento filosófico que, de certa forma, acabou influenciando seus alunos a terem participação ativa e significante durante as suas aulas.

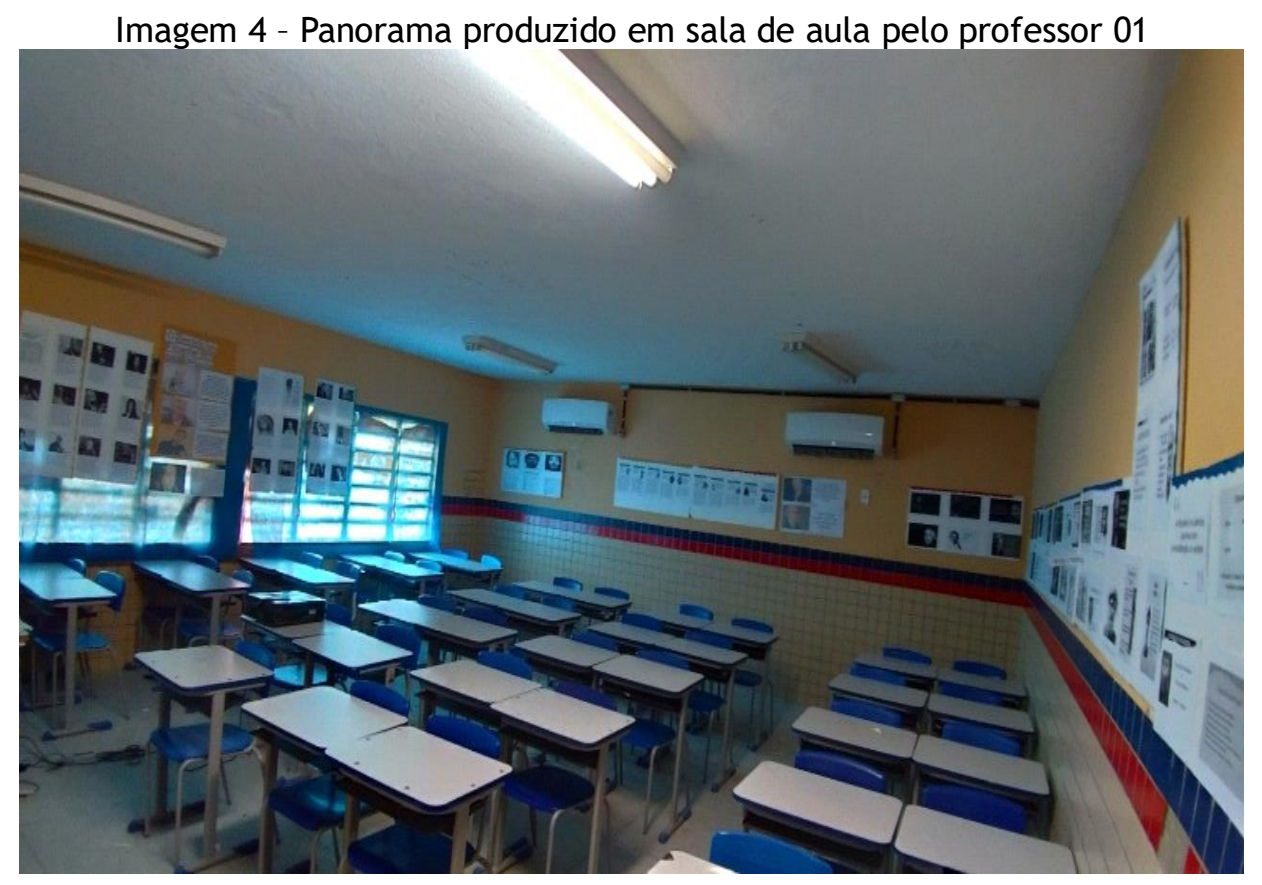

Fonte: 0 autor, 2019.

Quando perguntado ao professor 01 sobre em que consiste ensinar Filosofia sem ser filósofo, principalmente quando a turma é iniciante no ensino médio e os alunos nunca tiveram contato com a disciplina filosófica, ele ressaltou:

"Ensinar Filosofia é um desafio, e ao mesmo tempo uma paixão e aventura; não sou filósofo de formação, mas acredito que todos podemos ser filósofos. 
SILVA, J. P. B. (2020)

O sentido de filosofar em sala de aula

Tenho algumas dificuldades em relação a alguns conteúdos, mas sempre procuro superá-los, pesquisando e me aprofundando sobre algumas teorias filosóficas, bem como o pensamento dos filósofos que deram sua contribuição ao longo da História da Filosofia. Aprendi com Cerletti, que eu não conhecia, vim conhecer nestas aulas intervenções por seu intermédio, que "ensinar Filosofia é dar lugar ao pensamento do outro", foi justamente neste sentido, que tive a ideia e, por isso, idealizei o panorama no início do ano letivo com o percurso da História da Filosofia, para assim poder incentivar os meus alunos a não só aprender Filosofia, mas terem o gosto e desejo pelo filosofar. A Filosofia não deve ser uma questão privada, é preciso retirá-la deste mundo privado de uns poucos, e colocá-la ao acesso de todos inclusive de quem não é filósofo. Como professor de Filosofia tenho esta missão em minhas mãos, afinal, todos nós temos a capacidade de exercitar e aprender o filosofar". (Relato do professor 01).

A experiência do filosofar em sala de aula permitiu conhecer o universo de pensamento que os alunos e o professor 01 possuem, suas experiências, as diversas manifestações acerca de posicionamentos, questionamentos e até mesmo de interrogações sobre as diversas formas de ver e questionar o mundo e sua própria realidade. São experiências riquíssimas que, na maioria das vezes, passam despercebidas nos entornos da sala de aula. É preciso fazer, sim, uma Filosofia sem fronteiras, que contemple as experiências e a produção de sentido que antecede o pensamento de cada aluno e cada professor no experimentar do filosofar em sala de aula.

\section{Conclusões}

No percurso desta pesquisa, observamos os relatos dos alunos e do professor 01 acerca do filosofar, enquanto produção e construção de sentido da reflexão do pensamento filosófico, e acompanhamos a participação na experiência do filosofar em sala de aula. Percebemos que neste universo surgem encontros e desencontros, que alguns alunos são mais participativos e outros tímidos, e há também aqueles que desviam nossa atenção. Mesmo assim, são frutos de uma experiência única, aquela que antecede o seu próprio pensamento; são produtores de seus próprios conhecimentos, filósofos não de formação filosófica, mas que estão seguindo uma direção em busca deste real sentido, que é o desejo de alcançar o filosofar. Cada aluno se torna um filósofo, pois o ato do fazer filosófico implica o acontecimento da construção de um pensamento coletivo, que contempla o todo e não o privado.

Nesta intervenção, podemos repensar a nossa prática docente enquanto professor de Filosofia no ensino médio; afinal, não somos os únicos detentores do saber filosófico. 0 professor filósofo não é aquele que somente ensina conteúdos, mas aquele que faz de seu conteúdo uma investigação filosófica, na qual ele mesmo se torna um aprendiz e, juntamente com os seus alunos, percorre e trilha o caminho do filosofar. Portanto, é possível, sim, fazer Filosofia de uma maneira diferente. Como? Filosofando com nós mesmos, em especial à luz dos grandes filósofos que construíram, ao longo do tempo, uma produção de sentido filosófico, ou seja, um saber tão admirável que a História da Filosofia nos legou, e que nos causa espanto e admiração. Por isso, precisamos retirar a Filosofia do mundo privado de uns poucos, e colocá-la ao acesso de todos. 
SILVA, J. P. B. (2020)

O sentido de filosofar em sala de aula

\section{Referências}

BADIOU, Alain. A situação da filosofia no mundo contemporâneo. In. Para uma nova teoria do sujeito: conferências brasileiras. Rio de Janeiro: Relummé-Dumará, 1994.

BADIOU, Alain. La filosofía como repetición creativa. Acontecimiento, v. 17, n. 33-34.p. 123-131, 2007.

BADIOU, Alain. A aventura da filosofia francesa no século XX. Belo Horizonte: Autêntica. 2015.

CERLETTI, Alejandro. 0 ensino de filosofia como problema filosófico. Belo Horizonte: Autêntica, 2009.

CERLETTI, Alejandro; KOHAN, Walter O. La filosofía en la escuela: Caminos para pensar su sentido. Buenos Aires: Universid de Buenos Aires, 1996.

COMTE-SPONVILLE, André. Apresentação da Filosofia. São Paulo: Martins Fontes, 2002.

COMTE-SPONVILLE. Dicionário Filosófico. São Paulo: Martins Fontes, 2003.

DERRIDA, J. Le droit à la philosophie du point de vue cosmopolitique. Vêndôme: Unesco-Verdier, 1997.

GALLO, Sílvio. Metodologia do ensino de filosofia: uma didática para o ensino médio. Campinas: Papirus, 2012.

LARROSA, Jorge. Esperando não se sabe o quê: Sobre o ofício de professor. Belo Horizonte: Autêntica, 2018.

LARROSA, Jorge; RECHIA, Karen. P de professor. São Carlos: Pedro e João, 2018.

RANCIÈRE, Jacques. O mestre ignorante: Cinco lições sobre a emancipação intelectual. Belo Horizonte: Autêntica, 2009. 